\title{
DEVELOPMENT OF HIGH TEMPERATURE CAPABILITY P/M DISK SUPERALLOYS
}

\author{
E. S. Huron, K. R. Bain, D. P. Mourer ${ }^{1}$ and T. Gabb ${ }^{2}$ \\ ${ }^{1}$ GE Aviation, Cincinnati, OH. \\ ${ }^{2}$ NASA Glenn Center, Cleveland, OH.
}

Keywords: Superalloy, powder metallurgy, Boron, Carbon, Hafnium, Magnesium, Zirconium, Tantalum

\begin{abstract}
A study was conducted to optimize the major element chemistry of powder metallurgy (PM) alloys for the challenging goals of a High Speed Civil Transport (HSCT) application. Two iterations were performed. Subscale heats of experimental powders were atomized, consolidated by extrusion, isothermally forged, and supersolvus heat treated. Key relationships were identified between alloying elements resulting in the identification of an optimized alloy composition. The final alloy showed significant improvements in creep and in hold time crack growth compared to state-of-the art commercial alloys.
\end{abstract}

\section{Introduction}

In the mid-1990's, NASA began a program aimed at developing an engine for the High Speed Civil Transport (HSCT). This program included a materials-targeted effort called the Enabling Propulsion Materials (EPM) program and resulted in a joint contract effort between GE Aircraft Engines, Pratt \& Whitney, and NASA Glenn Research Center (formerly the NASA Lewis Center). The High Speed Civil Transport (HSCT) mission represented a unique durability challenge for compressor and turbine nickel-base superalloy disk materials. In a commercial subsonic transport engine, combined high operating temperature and stress conditions are encountered only during takeoff and thrust reverse after landing. The cumulative duration for both of these cycle points is typically only 3 to 5 minutes per mission cycle. Conversely, the highest operating temperature in the HSCT mission was to occur during the cruise portion of the mission cycle, with a duration of hours instead of minutes. As a consequence, the total hot time exposure over the life of an HSCT engine was to be many thousands of hours, as opposed to the 300 or so hot hours typically accumulated during the life of a subsonic transport engine. This imposed the need for a substantial improvement in the creep durability, surface integrity, and environmental resistance of disk alloys, and raised concerns regarding the possibility of highly deleterious dwellfatigue interactions resulting from the long hold times.

To develop superalloys to meet the challenge of the HSCT mission, the team reviewed prior published and unpublished superalloy data and immediately realized that successfully meeting the project goals would require alloys beyond the thencurrent commercial alloys (such as IN100 and Rene' 88DT), with improvements required in both bulk element composition and in grain boundary chemistry and structure. The team first explored grain boundary element composition and microstructural optimization (References 1 and 2) and then moved on to bulk alloy composition. This paper describes the results of the bulk alloy study, which was performed in two iterations.

First Iteration Alloy Matrix Design and Test Matrix
Screening tests on experimental alloys from earlier programs provided initial guidance on key factors that affect nickel-based superalloys. These key factors can be categorized into chemistry and microstructural effects. Following the completion of the initial grain boundary element Designed Experiment (DOE) (Reference 1), a series of strong chemistry trends on behavior were observed. Based on the earlier program screening results and the outcome of the grain boundary studies, the variation in chemistry, particularly tantalum, was found to be important. These trends were incorporated into a new designed experiment. The goal was to maintain good creep and dwell fatigue crack growth while simultaneously reducing solution temperature and enhancing process window. The key features were balancing tantalum, niobium and tungsten to increase creep resistance and lowering dwell fatigue crack growth resistance while controlling percent gamma prime, cobalt and $\mathrm{Al} / \mathrm{Ti}$ ratio to reduce the gamma prime solvus temperature. The selection of alloys for the first major element matrix (ME\#1) involved the variation of elements and of $\gamma^{\prime}$ volume fraction. This was achieved by varying the ratio of particular elements, such as $\mathrm{Al}: \mathrm{Ti}, \mathrm{W}: \mathrm{Mo}$, and $\mathrm{Nb}: \mathrm{Ta}$ while controlling the volume fraction of $\gamma^{\prime}$, which was varied from $48 \%$ to $55 \%$. These ratios are shown in Table 1.

Table 1: First Iteration Refinement Study Variables

\begin{tabular}{|c|c|c||}
\hline Ratio/ & Minimum & Maximum \\
Variable & & \\
\hline \hline $\mathrm{Al}: \mathrm{Ti}$ & $1: 1$ & $1.6: 1$ \\
$\mathrm{Mo}: \mathrm{W}$ & 0 & $2: 1$ \\
$\mathrm{Ta}: \mathrm{Nb}$ & 0 & $2: 1$ \\
\hline
\end{tabular}

Four additional alloys were concurrently processed with the ME\#1 material: CH98, A3, HK97, and HK81. These alloys were promising compositions from prior internal studies.

The full experimental design is shown in Table 2. In addition, several experimental alloys developed prior to the program were produced for evaluation. These alloys allowed exploration of the effects of lower chromium and cobalt along with higher niobium.

The test plan (Table 3) concentrated on tensile, creep, LCF and low temperature cyclic crack growth as well as high temperature time dependent crack growth. The effect of long time exposure was evaluated using an exposed creep specimen.

Table 2: First Iteration Alloy Development Matrix

(a) DOE Parameter Design Study of Nb/Ta, Al/Ti ratio, $\gamma$ ' Content, Co, Ta, and W/Mo. 


\begin{tabular}{|c||c|c|c|c|c|c|}
\hline \multicolumn{1}{|c||}{} & \multicolumn{5}{|c|}{ Design-of-Experiment Matrix } \\
\cline { 2 - 7 } & Nb/Ta & Al/Ti & $\% \gamma^{\prime}$ & Co & Ta & W/Mo \\
\hline ME1-1 & L & L & L & L & L & L \\
\hline ME1-2 & L & L & L & H & H & H \\
\hline ME1-3 & L & L & H & L & H & H \\
\hline ME1-4 & L & L & H & H & L & L \\
\hline ME1-5 & L & H & L & L & H & L \\
\hline ME1-6 & L & H & L & H & L & H \\
\hline ME1-7 & L & H & H & L & L & H \\
\hline ME1-8 & L & H & H & H & H & L \\
\hline ME1-9 & H & L & L & L & L & H \\
\hline ME1-10 & H & L & L & H & H & L \\
\hline ME1-11 & H & L & H & L & H & L \\
\hline ME1-12 & H & L & H & H & L & H \\
\hline ME1-13 & H & H & L & L & H & H \\
\hline ME1-14 & H & H & L & H & L & L \\
\hline ME1-15 & H & H & H & L & L & L \\
\hline ME1-16 & H & H & H & H & H & H \\
\hline
\end{tabular}

(b) Actual Element Levels for First Iteration Refinement Alloys.

\begin{tabular}{|c||cc|c|c|c|c|c|c|}
\hline \multicolumn{1}{|c|}{} & \multicolumn{7}{|c|}{ Design-of-Experiment Matrix } \\
\cline { 2 - 10 } Alloy & $\mathrm{Nb}$ & $\mathrm{Ta}$ & $\mathrm{Al}$ & $\mathrm{Ti}$ & $\mathrm{Co}$ & $\mathrm{Mo}$ & $\mathrm{Cr}$ & $\mathrm{W}$ \\
\hline $\begin{array}{c}\text { ME1 Low } \\
\text { LEVEL }\end{array}$ & 0 & 1 & 2.4 & 3 & 13.5 & $\begin{array}{c}3.8 \\
\text { AVG. }\end{array}$ & $\begin{array}{c}13.5 \\
\text { AVG. }\end{array}$ & 0 \\
\hline $\begin{array}{c}\text { ME1 High } \\
\text { LEVEL }\end{array}$ & 1.6 & 2.9 & 4.1 & 5.6 & 18.3 & N/A & N/A & 1.9 \\
\hline A3 & 1.6 & 0 & 2.4 & 4.7 & 17 & 4.6 & 15.3 & 0 \\
\hline HK81 & 3.6 & 3.4 & 3.5 & 2.6 & 7.8 & 3.4 & 13.9 & 0 \\
\hline HK97 & 1.3 & 2.4 & 4 & 3.5 & 9.5 & 3.9 & 15.9 & 0 \\
\hline CH98 & 0 & 3.5 & 3.6 & 3.9 & 18.2 & 3.7 & 12.6 & 0 \\
\hline
\end{tabular}

Table 3: First Iteration Alloy Refinement DOE Evaluation Test Plan

\begin{tabular}{|c|c|c|}
\hline Test Type & $\begin{array}{c}\text { Test } \\
\text { Quantity }\end{array}$ & Test Conditions \\
\hline Tensile & 2 & $427 \mathrm{C}$ \\
& 2 & $649 \mathrm{C}$ \\
\hline $\begin{array}{c}\text { Time to 0.2\% } \\
\text { Creep }\end{array}$ & 1 & 649C/793MPa (Post \\
& 1 & Exposure 760C/500 hours) \\
& 2 & 704C/620MPa \\
Low Cycle & 1 & 649C/793Mpa \\
Fatigue & 1 & Range; unpeened \\
& & 538C; R=0; 0.69\% Strain \\
& 2 & Range; Peened \\
\hline FCGR & & 704C; 2 hr dwell \\
& & 427C; R=0.1; 20 cpm \\
\hline
\end{tabular}

Alloy Processing
For both the initial ME\#1 matrix and the ME\#2 matrix described later, material was processed using standard $\mathrm{P} / \mathrm{M}$ techniques, using gas-atomized powder. The powder for ME\#1 was produced using a laboratory scale atomizer at GE Global Research Center (GE-GRC) in Schenectady, NY, and the powder from ME\#2 was processed from laboratory scale heats from Homogeneous Metals, Inc. (HMI), Clayville, New York. Powder for both the ME\#1 and the ME\#2 matrices were consolidated, isothermally forged, and heat treated using procedures like those for the earlier grain boundary element study and described elsewhere (Reference 1 ).

\section{First Iteration Alloy Refinement Tensile Results}

The 649C supersolvus processed alloy tensile results for the first iteration major element designed experiment are shown in Figure 1. In all of the comparisons that follow, the two best alloys from the overall study were ME1-12 and ME1-16. These two alloy combinations clearly were among the best in tensile strength. While not shown, the results at 427C were very similar in ranking to the $649 \mathrm{C}$ results.

\section{First Iteration alloy Refinement Creep Results}

The creep results for the ME\#1 alloys are shown in Figure 2. A comparison of the creep results as a function of heat treatment at 649C and 704C is shown in Figure 2. ME1-12 and ME1-16 are by far the best alloys at 649C. At 704C these two alloys were still among the best. In addition, results of post exposure creep testing indicated that both of these alloys retained the highest percentage of unexposed creep capability (Figure 3).

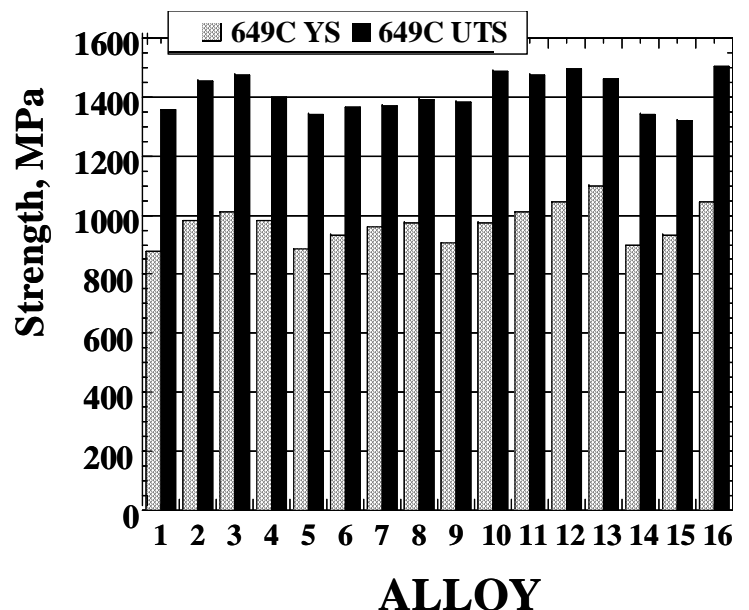

Figure 1: The average of duplicate tensile tests at 649Cfor each of the first iteration refinement ME\#1 DOE alloys is shown. Several of the alloys achieve the program goals. Trends at 427C were similar. 


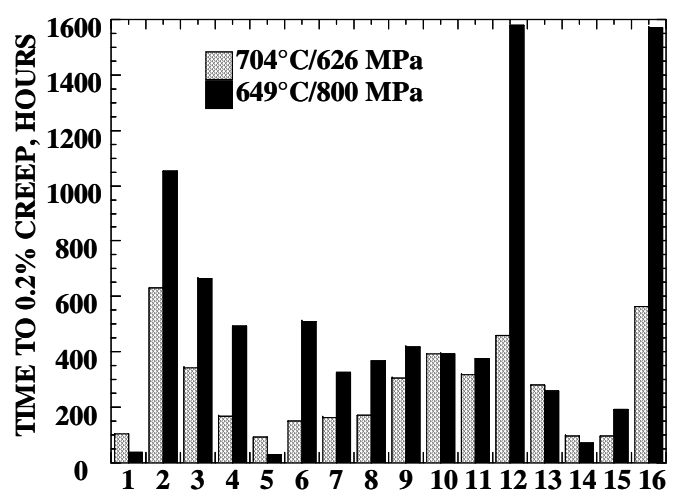

ALLOY

Figure 2: Average creep results of major element ME\#1 DOE alloys at both test temperatures. Alloys ME1-12 and ME1-16 were clearly the best.

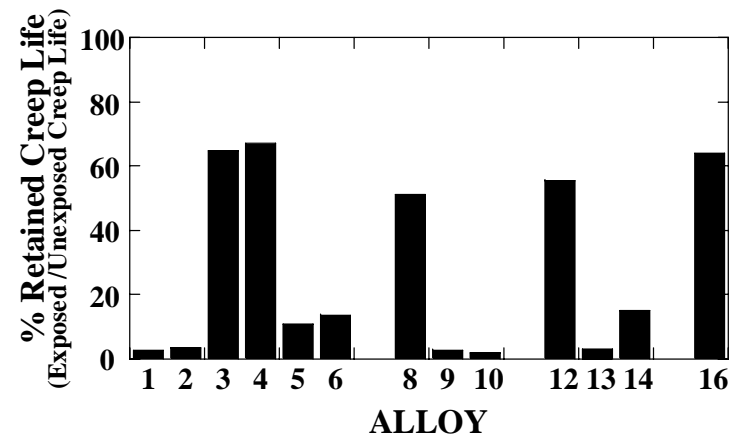

Figure 3: $M E \# 1$ alloys were given a furnace exposure of $760 \mathrm{C} / 500$ hours to simulate an engine exposure of 9000 hours at 704C. Alloys with high amounts of gamma prime retained nearly $60 \%$ of their unexposed capability while those with less gamma prime retained less than 10\% (note: data for alloys 7, 11 and 15 were not collected).

\section{First Iteration Alloy Refinement LCF Results}

A series of low cycle fatigue tests was conducted on each of the major element DOE alloys.

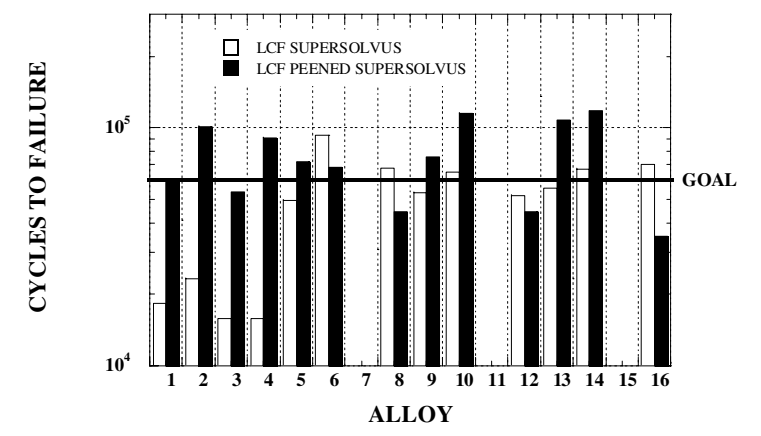

Figure 4: Major element ME\#1 DOE alloys LCF results indicated several alloys can achieve the LCF goal of the program (60K cycles at the test condition). Peening the surfaces enhanced the lives of the alloys.
One specimen was run as machined while a duplicate test was completed with a peened surface. The effect of peening was generally to improve the behavior of the supersolvus processed material (Figure 4).

There was no obvious trend with the DOE variables. Grain size was most likely the key-determining factor on life at these test conditions, and grain sizes were similar. In addition, the pilotscale atomization facilities probably resulted in variation in powder particle size and inclusion distributions.

\section{First Iteration Alloy Refinement Fatigue Crack Growth Results}

The effect of alloying and processing was investigated at two test conditions. Testing was conducted at 704C with a two-hour dwell at maximum load to measure the time dependent crack growth behavior of the alloys (a key program goal). Testing was also conducted at $427 \mathrm{C}$ at $20 \mathrm{cpm}$ with no dwell to measure the cyclic fatigue crack growth behavior.

The overall results for the 16 ME\#1 DOE alloys when tested at 427C condition are shown in Figure 5. Scatter in results is typical for alloys with a uniform grain size when comparing cyclic FCGR. Approximately 2x scatter was observed and no significant trend on chemistry was observed. Comparing the cyclic results to the projected goal properties for the alloys indicated that all of the alloys achieved the goals.

Figure 6 shows the range of FCGR results for the ME\#1 alloys when tested at 704C with the two-hour dwell time. All crack growth comparisons discussed in this paper are made at the same nominal $\Delta \mathrm{K}$ comparison point of $33 \mathrm{MPa} \sqrt{\mathrm{m}}$ reported earlier for the Grain Boundary work (References 1 and 2). Scatter in results was far less than observed in the prior data screening of existing alloys, but was still 50x from fastest to slowest alloy across the experiment. The range of results is usually far greater when comparing alloys for time dependent crack growth behavior. This result suggested two observations one, that the testing and processing was well controlled across the experiment, and two, that chemistry did have an influence, and that optimization of alloy composition had high promise to positively influence crack growth. Alloys ME1-12 and ME1-16 gave the best balance of dwell FCGR behavior and continuous cycling crack growth resistance.

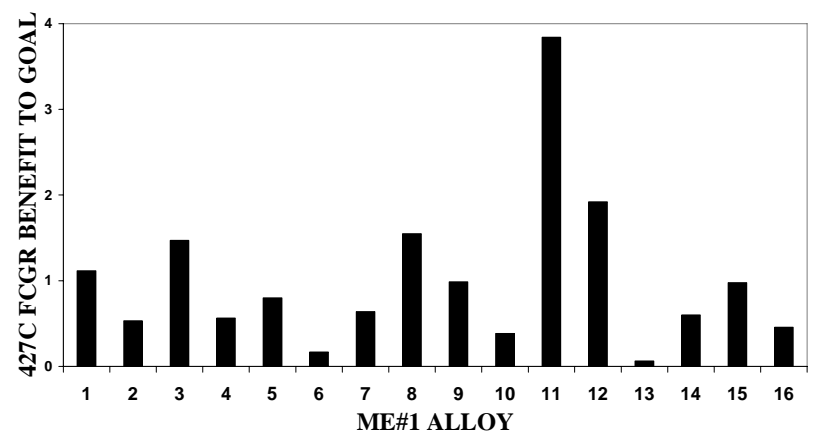

Figure 5: All major element alloys tested achieved the goal cyclic FCGR behavior. Low temperature cycle dependent FCGR of major element DOE alloys indicated only typical testto-test scatter and no strong trends on alloy chemistry 


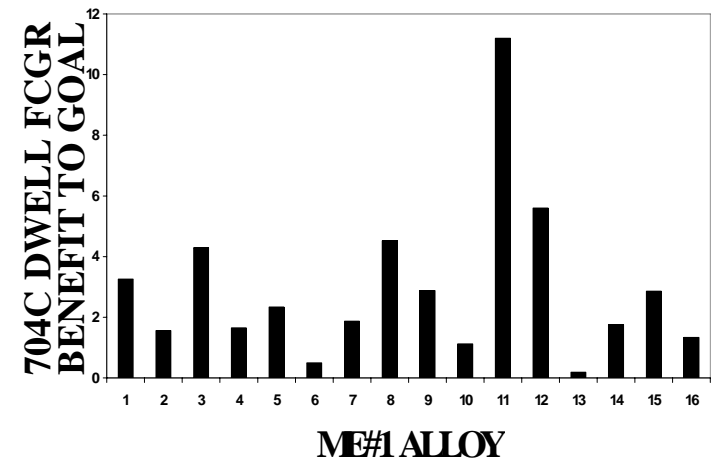

Figure 6: Comparison of crack growth rates for 704C 2 hour dwell condition. The major element ME\#1 DOE alloys all showed relatively good dwell FCGR. Behavior improved as compared to the program goals at lower stress intensity factor. The effect of alloy chemistry is far more apparent in dwell FCGR testing than continuous cycling data

\section{First Iteration Alloy Refinement Microstructural and Fractographic Characterization}

Characterization of the structure of first iteration refinement alloys was performed to document the alloys microstructures and correlate mechanical properties to the structures. Microstructural and phase analyses were performed using optical metallography, scanning electron microscopy (SEM), transmission electron microscopy (TEM). Chemical analysis included wet chemical techniques for general alloy chemistry and energy dispersive analysis (EDS) for phase chemistry. Selected area diffraction (SAD) was also used for phase analysis and identification. Evaluations of the alloy structures were performed using sections of low cycle fatigue and fatigue crack growth specimens. In addition to microstructural features, fractography of tested LCF and FCG samples was performed to identify failure initiations (LCF) and fracture path morphologies (FCG).

Evaluations of structures showed the measured average grain sizes varied over an approximate 4 ASTM range among the alloys, ASTM 3.7 to 7.5. The majority of the ME\#1 alloys average grain sizes ranged from ASTM 3.6 to 6.4 with the larger average grain sizes found in Alloys ME1-1, ME1-9 and ME1-7. As-large-as grain sizes were found to range from ASTM -0.9 to 2.6 in the alloys evaluated. A typical microstructure representative of the ME\#1 matrix with a grain size of ASTM 5.8 is shown in Figure 7.

Primary cooling gamma prime sizes ranged from $0.22 \mu \mathrm{m}$ to $0.53 \mu \mathrm{m}$. As a result of natural cooling rate variations in the pancakes (OD cooling faster than ID) the FCG specimens (from near the center of machined alloy pancakes) exhibited coarser gamma prime sizes than LCF samples (machined from nearer the OD of the pancake). Analysis of the distributions of the primary cooling gamma prime showed some alloys to exhibit a dual distribution. Representative structures for ME1-12 and ME1-16 are shown in Figure 8. Fine gamma prime sizes ranged from approximately $26.1 \mathrm{~nm}$ to $39.6 \mathrm{~nm}$ with ME1-16 exhibiting the smallest size $(26.1 \mathrm{~nm})$. Six of the 16 Major Element
Iteration alloys comprising the DOE matrix exhibited cellular (fan shaped) gamma prime which tended to distort the grain boundaries. These structures appeared to form on quench from the supersolvus solution temperature and were found in alloys with very small supersolvus heat treat windows.

Evaluation of grain boundaries and grain boundary carbides in the supersolvus heat treated alloys showed MC and $(\mathrm{Cr}, \mathrm{Mo}, \mathrm{W})_{23} \mathrm{C}_{6}$ carbides to be similar in size and distribution among the alloys evaluated. The composition of $(\mathrm{Cr}, \mathrm{Mo}, \mathrm{W})_{23} \mathrm{C}_{6}$ carbides were found to be relatively consistent among the alloys evaluated while the refractory content $(\mathrm{Ti}, \mathrm{Ta}, \mathrm{Nb})$ of $\mathrm{MC}$ carbides varied with alloy composition. The grain boundaries tended to be loaded with $(\mathrm{Cr}, \mathrm{MoW})_{23} \mathrm{C}_{6}$ carbides but continuous films were not observed. In addition to $\mathrm{MC}$ carbides (Ti,Mo) ${ }_{6} \mathrm{C}$ carbide needles were observed in the matrix of several alloys evaluated.

Low cycle fatigue initiation origins were typically grain facets. In general peening tended to increase fatigue life and result in internal initiations. However, the few instances of lower peened lives (compared to the companion unpeened LCF test) indicate the peening conditions used in this study may have been borderline aggressive for these alloys. The average grain sizes of the LCF specimens were found to positively correlate with LCF lives - finer grained alloys exhibiting longer lives as shown in Figure 4. The measured as-large-as grain sizes showed a similar trend with fatigue life.

Fatigue crack growth morphology resulting from 704C/2 hr dwell testing was primarily intergranular in all of the alloys. The degree of intergranular fatigue path morphology correlated with hold time crack growth rates. Alloys with fracture paths displaying more highly defined grain boundary features had faster 704C/2 hour dwell fatigue crack growth rates than those exhibiting a mixed mode. Transgranular crack growth morphology was found for all alloys tested 427C/20 CPM.

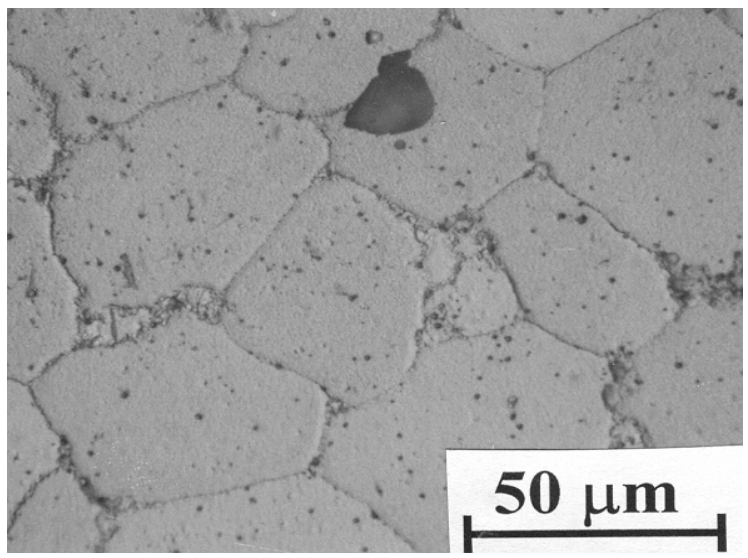

Figure 7: Typical Microstructure for alloys in this study after supersolvus processing; grain sizes were typically ASTM 5-7. 


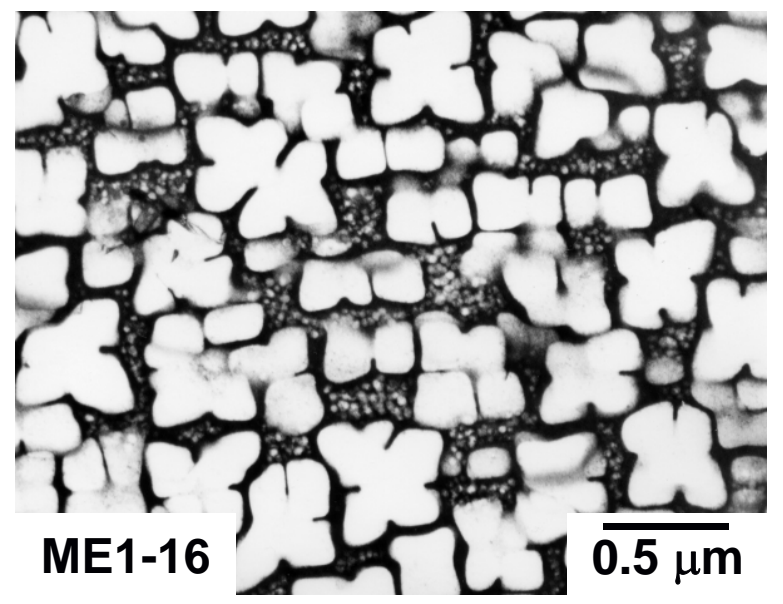

(a) Structure of ME1-12.

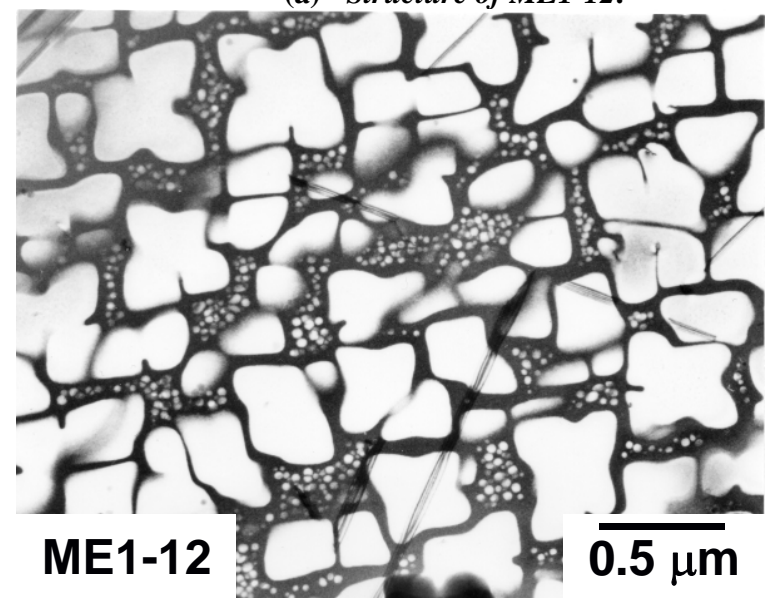

(b) Structure of ME1-16.

Figure 8: Typical $\gamma$ ' microstructures of ME\#1 alloys.

\section{First Iteration Alloy Refinement Statistical Data Analysis}

The property data from the Major Element (ME\#1) DOE experiment were analyzed to identify the most promising alloy compositions and help guide further alloy refinement efforts. Statistical methods were used to identify those variables in the designed experiment that affect mechanical properties and to establish relationships that could be used to predict the performance of future alloys.

The ME\#1 DOE entailed six independent parameters and employed a quarter-fraction factorial design $\left(2_{I V}^{6}{ }^{2}\right)$ with resolution sufficient to avoid confounding between main effects and two-factor interactions. The DOE contained sixteen alloys. The parameters of the DOE were cobalt, volume fraction gamma-prime, aluminum-titanium ratio, niobium-tantalum ratio, tantalum, and tungsten concentration. The mechanical property responses included dwell fatigue crack growth rate, creep life, and tensile properties.
The initial statistical analysis of the ME\#1 DOE entailed calculating each of the fifteen contrasts and judging the significance of potential effects by estimating the standard-errorof-the-effect, calculating t-statistics, and plotting contrasts and model predictions versus standard deviates. This treatment of the data paralleled the Box and Hunter approach (Reference 3) and was implemented using a standard spreadsheet template. Although the analysis was hampered by missing data entries, the analysis indicated that volume fraction gamma-prime, tantalum, and tungsten produced significant effects. Tungsten concentration and volume fraction gamma-prime affected each of the three property categories whereas tantalum principally affected tensile properties. This treatment of the data failed to identify any strong effects associated with the element-ratio parameters of the DOE. Further statistical analysis involving multiple regression was carried out for the ME\#1 DOE data set. The regression analysis produced a series of linear equations describing the influence of the independent variables upon each of the mechanical property categories. Although the fidelity of these relationships varied, two-thirds of the regression equations had regression coefficients $\left(r^{2}\right)$ that exceeded 0.74. These equations provided understanding of the property trends among the sixteen alloys of the ME\#1 DOE as well as identification of variables important to future alloy refinement efforts. The association between compositional elements and mechanical property response is presented in Figure 9. This chart shows that each alloy element has an important contribution to the performance of the material; the key is to achieve a proper balance because no single compositional variable dominates overall alloy mechanical property response.

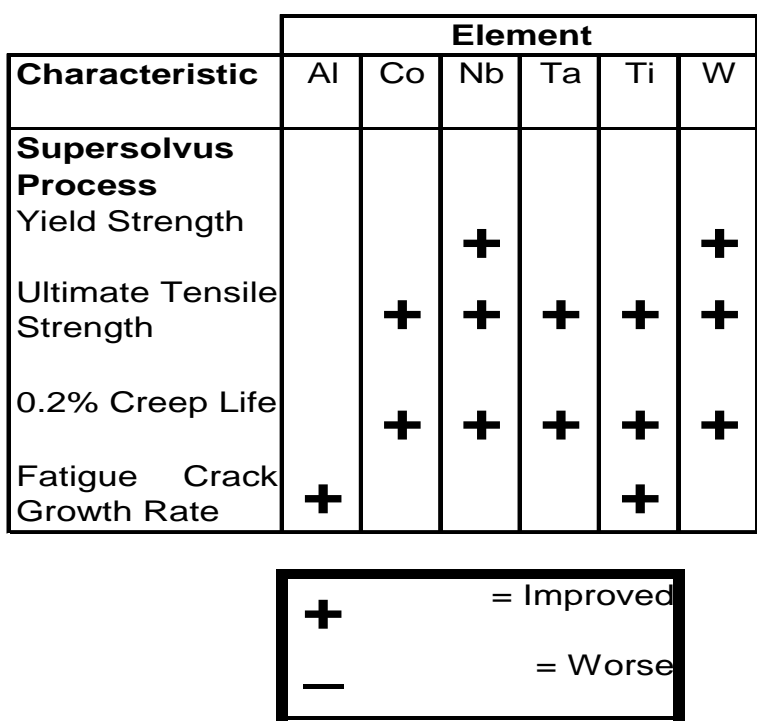

Figure 9: Statistically determined effect of alloying element for key mechanical property characteristics. In the ranges studied all the added elements correlated positively with the properties tested.

Comparing Figure 9 to the high and low values of the various factors in the DOE (Table 2), showed that higher Ta, Mo, Al, $\mathrm{Co}, \mathrm{W}$, and Ti were generally desirable. Taking all of the alloys as a group, the overall results of the first iteration major element designed experiment can be assessed further by comparing the 
alloy test results in a plot of dwell FCGR versus time to $0.2 \%$ creep. This type of a plot emphasizes the high temperature capability of an alloy. Figure 10 compares the results of this DOE to the GBE\#2 designed experiment detailed in Reference 1. In addition, the results for the added alloys outside of the DOE framework from both GBE\#2 and ME\#1 were added with leading other alloys. Alloy chemistry clearly influenced properties. Alloy ME1-12 and ME1-16 were the best. Comparing the best two major element DOE alloys to thencurrent production alloys (Figure 11) indicated a significant improvement in either dwell fatigue crack growth resistance and/or creep resistance with the advanced alloys.

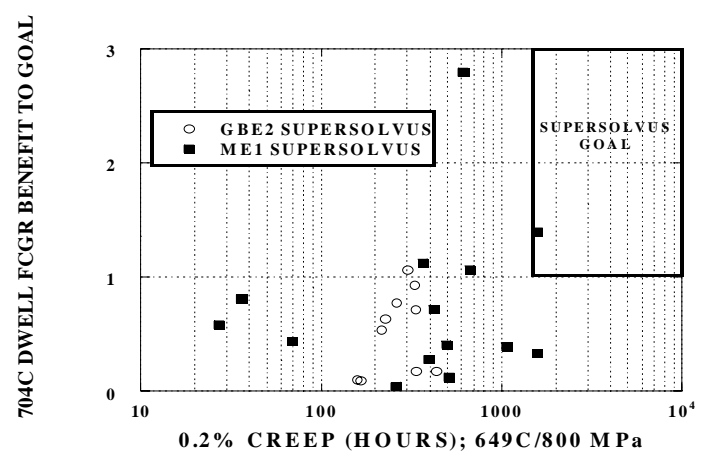

Figure 10: A comparison of the balance of dwell FCGR and creep behavior of all of the combinations of alloy chemistry and heat treatment indicated the best combinations of processing/chemistry could achieve the aggressive goals of the HSCT disk alloy.

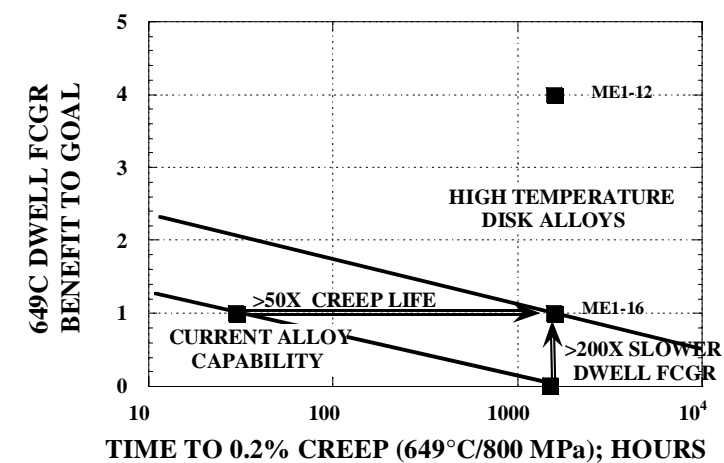

Figure 11: Best major element design-of-experiment alloys are significantly superior to prior production alloys when considering the balance of creep and high temperature crack growth. The best chemistries were ME1-12 and ME1-16.

Examination of the individual alloys of the ME-1 DOE matrix indicated that two alloys (alloy ME1-12 and alloy ME1-16) exhibited very good creep, fatigue crack growth rate, and tensile properties. ME1-12 and ME1-16 had high Nb/Ta, high volume fraction of $\gamma^{\prime}$, high Co, and high $\mathrm{W}$, while they differed in $\mathrm{Al} / \mathrm{Ti}$ ratio and amount of Ta. Although several other alloys of the ME\#1 series showed superior performance for a single property value, ME1-12 and ME1-16 exhibited the best overall balance of properties. In addition, both alloys had mechanical properties that were nearly as good as the best alloy in each of the three property categories. Consequently, ME1-12 and ME1-16 chosen as the basis for further work.

\section{Second Iteration Alloy Refinement Approach}

The team proceeded to design the ME\#2 DOE series of alloys in an attempt to refine the alloy composition. The DOE design consisted of a base matrix containing eight alloys, a centerpoint alloy, and four additional alloys. The objective of this alloy DOE design was to achieve modest property improvements compared to ME1-12 and ME1-16 while increasing the heat treatment window to improve alloy processability. The best alloy from the first iteration alloy refinement study was alloy ME1-16. As discussed above, this alloy chemistry serves as the base composition of the second iteration alloy refinement study. This alloy met the HSCT disk lifing and strength goals and possessed the best balance of mechanical properties for potential process routes envisioned. It also exhibited the best processability in terms of heat treat window. The heat treat window is defined as the difference between the $\gamma^{\prime}$ solvus temperature and the incipient melt temperature of an alloy. The greater this difference, the greater the heat treat window. Even though ME1-16 did have the best heat treat window of the alloys studies in the first iteration alloy refinement, its window was still relatively small when compared to other $\mathrm{P} / \mathrm{M}$ nickel disk alloys in common usage. Therefore, there was a desire to increase this window to make processing of the alloy as robust as possible.

The ME1-12 and ME1-16 were very similar alloys; ME1-12 had higher titanium content whereas ME1-16 had high tantalum and niobium concentrations. The base matrix for the ME\#2 alloy series was designed to:

- include higher cobalt concentration to increase the heat treatment window,

- vary the Al:Ti ratio and the tungsten and niobium concentration as principal DOE variables,

- include magnesium concentration as a blocking variable, and to

- use ME1-16 as the basis for the matrix centerpoint; however, with higher cobalt (processability) and a small reduction in niobium and tantalum concentrations.

The four additional alloys of the series were selected to investigate the influence of boron and cobalt level on a base alloy composition similar to that of ME1-16.

The design of the ME\#2 DOE series of alloy compositions was guided by the regression relationships developed from the ME\#1 data set. Predictive calculations using the regression relationships showed that ME\#2 alloys were predicted to have superior creep and equivalent dwell fatigue crack growth capability to the best ME\#1 alloys.

Based on the analysis of the first iteration experiment, the second iteration alloy refinement study was actually made up of two alloy matrices (Table 4). The first was an L9 statistical design of experiments (DOE) matrix based on the composition of the best alloy resulting from the first major element matrix. The alloying elements varied as a part of the L9 DOE were tungsten, niobium, aluminum/titanium ratio, and magnesium. In addition to determining the influence of these elements on 
properties, the elemental levels selected for study were also chosen to help establish the elemental specification limits for the final down selected alloy. The second matrix was an L4 DOE, also based on the best alloy from ME\#1, but the niobium and tungsten levels were reduced slightly to limit the total refractory content and reduce the projected alloy density. This L4 matrix focused on the effects of modifying boron and cobalt levels on mechanical properties and alloy processibility. This latter matrix was added to the study to reduce the risk to the program by evaluating some alloys closer in composition to the best alloy from the ME\#1 study to complement the greater variation in the L9 DOE.

Table 4 Comparison of Planned Variation Between ME1-16 and the Base Chemistry of the L9 and L4 ME\#2 Matrices.

\begin{tabular}{|c|c|c|c|c|c|c|c|c|}
\hline Alloy & $\mathrm{Al}$ & $B$ & $\mathrm{Co}$ & $\mathrm{Nb}$ & $\mathrm{Ta}$ & $\mathrm{Ti}$ & W & $\mathrm{Mg}$ \\
\hline $\begin{array}{c}\text { ME1 } \\
-16\end{array}$ & 3.5 & 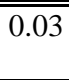 & $=18.2$ & 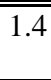 & 2.7 & 3.5 & $\begin{array}{l}1.9 \\
\end{array}$ & 0 \\
\hline $\begin{array}{c}\text { L9 } \\
\text { ME } \\
\# 2 \\
\text { Base }\end{array}$ & $\begin{array}{c}3.2 \\
\text { to } \\
3.7\end{array}$ & 0.03 & 20.0 & $\begin{array}{c}0.8 \\
\text { to } \\
1.4\end{array}$ & 2.25 & $\begin{array}{c}3.5 \\
\text { to } \\
4.0\end{array}$ & $\begin{array}{c}1.5 \\
\text { to } \\
2.3\end{array}$ & $\begin{array}{c}0 \\
\text { to } \\
0.005\end{array}$ \\
\hline $\begin{array}{c}\text { L4 } \\
\text { ME\# } \\
2 \\
\text { Base }\end{array}$ & $\begin{array}{c}3.4 \\
5\end{array}$ & $\begin{array}{c}0.02 \\
\text { to } \\
0.03\end{array}$ & $\begin{array}{c}18.0 \\
\text { to } \\
21.5\end{array}$ & 1.1 & 2.7 & 3.6 & 1.5 & 0 \\
\hline
\end{tabular}

Table Notes:

1. Italicized Values: Elements modified to improve processibility or to limit total refractory content.

2. Bold Face Values: Elements actually being varied in the alloy matrix to determine their influence on properties and processibility.

Table 5 Second Iteration Alloy Actual Compositions. The L9 Matrix Consists of Alloys ME2-1 through 9. The L4 Matrix Consists of Alloys ME2-10 through 13.

\begin{tabular}{|c|c|c|c|c|c|c|c|c|c|}
\hline \multirow{2}{*}{$\begin{array}{c}\text { Alloy } \\
\text { Matrix }\end{array}$} & \multirow{2}{*}{$\begin{array}{c}\text { Alloy } \\
\text { Name }\end{array}$} & \multicolumn{9}{|c|}{ Alloying Element Levels } \\
\cline { 3 - 10 } & & $\mathrm{Al}$ & $\mathrm{B}$ & $\mathrm{Co}$ & $\mathrm{Nb}$ & $\mathrm{Ta}$ & $\mathrm{Ti}$ & $\mathrm{W}$ & $\mathrm{Mg}$ \\
\hline \hline L9 & ME2-1 & 3.2 & 0.03 & 20.6 & 0.81 & 2.3 & 4 & 1.5 & 0 \\
\hline L9 & ME2-2 & 3.4 & 0.03 & 20.5 & 1.5 & 2.2 & 3.7 & 1.4 & 0.027 \\
\hline L9 & ME2-3 & 3.4 & 0.03 & 20.2 & 0.77 & 2.2 & 3.9 & 2.2 & 0.026 \\
\hline L9 & ME2-4 & 3.3 & 0.03 & 20.2 & 1.5 & 2.2 & 4 & 2.3 & 0 \\
\hline L9 & ME2-5 & 3.7 & 0.03 & 20.8 & 0.8 & 2.3 & 3.2 & 1.5 & 0.01 \\
\hline L9 & ME2-6 & 3.7 & 0.03 & 20.5 & 1.4 & 2.2 & 3.2 & 1.5 & 0 \\
\hline L9 & ME2-7 & 3.6 & 0.03 & 20.7 & 0.79 & 2.2 & 3.2 & 2.2 & 0 \\
\hline L9 & ME2-8 & 3.8 & 0.03 & 20.3 & 1.4 & 2.2 & 3.3 & 2.2 & 0.029 \\
\hline L9 & ME2-9 & 3.5 & 0.03 & 20.4 & 1.2 & 2.2 & 3.6 & 1.9 & 0 \\
\hline \hline L4 & ME2-10 & 3.4 & 0.018 & 18 & 1.1 & 2.6 & 3.7 & 1.4 & 0 \\
\hline L4 & ME2-11 & 3.4 & 0.017 & 21.9 & 1.1 & 2.5 & 3.6 & 1.4 & 0 \\
\hline L4 & ME2-12 & 3.4 & 0.028 & 17.9 & 1.1 & 2.7 & 3.7 & 1.4 & 0 \\
\hline L4 & ME2-13 & 3.5 & 0.03 & 21.7 & 1.1 & 2.6 & 3.6 & 1.4 & 0 \\
\hline
\end{tabular}

The aim alloy elemental levels for the L9 and L4 DOE's are shown in Table 4 and the actual levels attained are shown in Table 5. A comparison of these two tables shows the aims were achieved with reasonable success, with the exception of magnesium, which is extremely difficult to control due to its highly reactive nature.

Second Iteration Alloy Refinement Test Plan

The test plan consisted of tensile, notch tensile, creep, stress rupture and fatigue crack growth (FCGR). The test plan is presented in detail in Table 6. Low cycle fatigue was not tested in this study because the second iteration alloys were produced in a pilot plant facility in small heat lots. These two factors can negatively bias the LCF lives of experimental material through the introduction of non-metallic inclusions and porosity. The second iteration test plan required two forgings per alloy.

Table 6: Mechanical Property Test Matrix for Second Iteration Refinement Alloys

\begin{tabular}{|c|c|c|c|c|}
\hline $\begin{array}{c}\text { Test } \\
\text { Type }\end{array}$ & Qty & $\begin{array}{c}\text { Temperature } \\
\left({ }^{\circ} \mathrm{C}\right)\end{array}$ & $\begin{array}{c}\text { Stress } \\
(\mathrm{MPa})\end{array}$ & $\mathrm{K}_{\mathrm{t}}$ \\
\hline Tensile & 6 & $25-704$ & & 1.0 \\
\hline $\begin{array}{c}\text { Notch } \\
\text { Tensile }\end{array}$ & 4 & $538-649$ & & $\begin{array}{c}2.5- \\
3.5\end{array}$ \\
\hline Creep & 12 & $649-787$ & $790-414$ & 1.0 \\
\hline $\begin{array}{c}\text { Combo } \\
\text { Rupture }\end{array}$ & 3 & $732-621$ & $965-621$ & 2.7 \\
\hline FCGR & 2 & 427 & $20 \mathrm{cpm}$ & NA \\
\hline HT FCGR & 2 & 704 & $\begin{array}{c}2 \text { hour } \\
\text { hold }\end{array}$ & NA \\
\hline
\end{tabular}

\section{Second Iteration Alloy Refinement Tensile Results}

Tensile results are shown in Figure 12 and 13. The alloys ME23, ME2-7, ME2-9 and were observed as having the best balance of all tested, and formed the basis for selecting the final HSCT disk alloy composition.

\section{Second Iteration Alloy Refinement Creep/Rupture Results}

The creep behavior was one of the key properties expected to vary with composition in the ME\#2 DOE plan. Maintaining adequate creep strength while also keeping dwell FCGR low was imperative. The results for alloys ME2-1 through ME2-13 are shown in Figure 14. Alloys with higher tantalum and titanium had superior creep. ME2-9 was the centerpoint alloy in the L9 DOE matrix and was one of the better alloys.

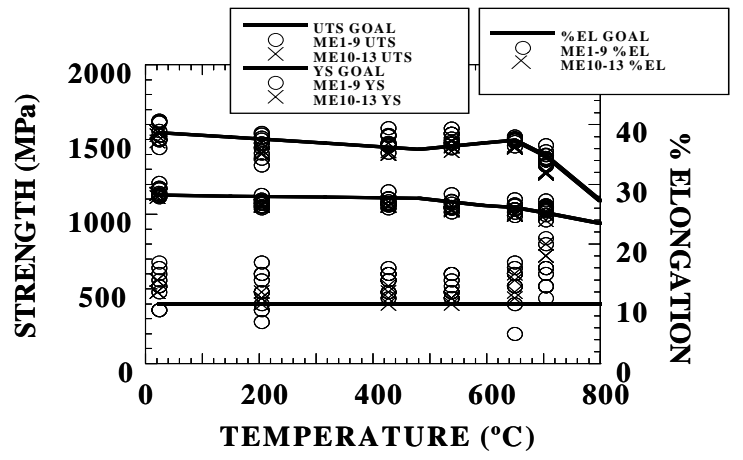

Figure 12: Strength properties for ME\#2 Alloys. On average the alloys meet or exceeded the goal projected properties for the program.

Stress rupture results are summarized in Figure 15. Alloys with higher tantalum and the L9 DOE alloy ME2-9 had superior rupture. Alloy ME2-1 was the best alloy in both creep and rupture, but was found to be lacking when reviewing the dwell FCGR results. 


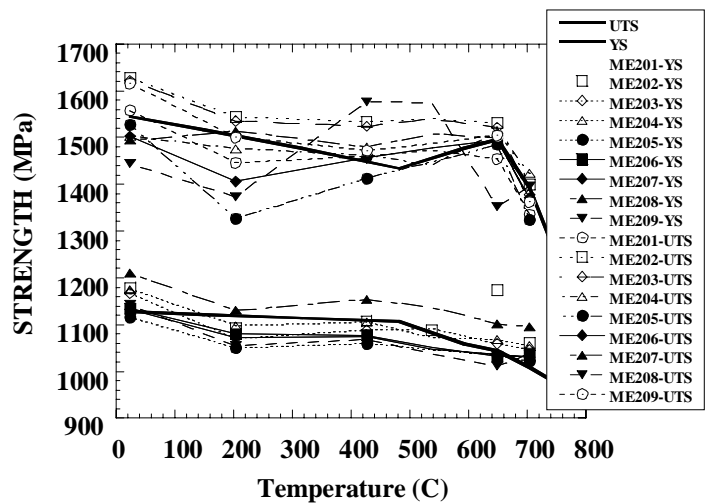

Figure 13: A comparison of individual UTS and 0.2\% Yield Strength results for alloys ME2-1 through ME2-9.

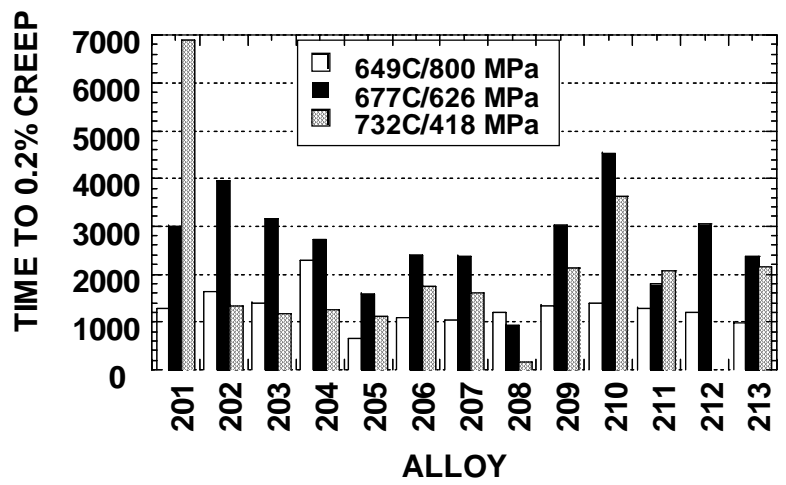

Figure 14: Comparison of creep capability for all ME\#2 alloys indicated that alloys with higher tantalum and higher titanium had superior creep.

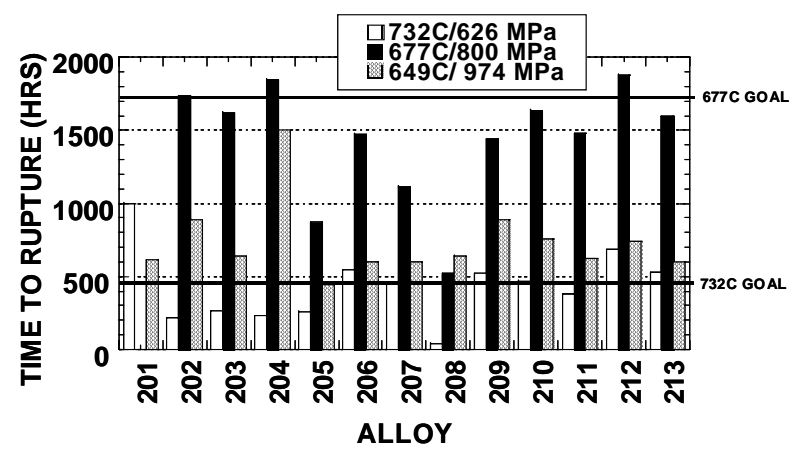

Figure 15: Stress rupture results indicated the higher temperature goals were achievable, but the lower temperature (higher stress) goal was too high.

\section{Second Iteration Fatigue Crack Growth Properties}

The $20 \mathrm{cpm}$ fatigue crack growth was measured via electrical potential drop on a notched and pre-cracked surface flaw specimen. The results are shown in Figure 16. Improving the $20 \mathrm{cpm}$ FCGR behavior will be the major challenge in scale-up of the down-selected composition.
The dwell fatigue crack growth behavior was measured at 704C using the same technique as was employed in the 20 cpm FCGR testing. A two-hour dwell at maximum load was used to simulate the types of dwell expected in the HSCT engine at the high temperature/high stress condition. Results are shown in Figure 17. The L4 DOE alloys as a group were superior to the L9 alloys. Note that the L4 DOE alloys were higher in Ta than the L9 alloys.

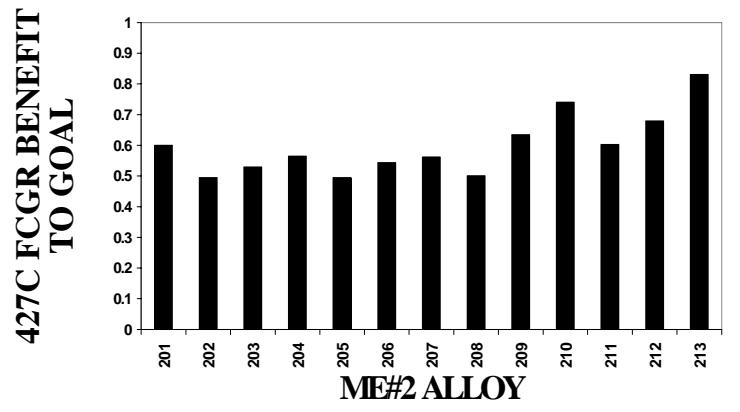

Figure 16: ME\#2 20 cpm FCG Results. All of the alloys were faster than the goal.

\section{Second Iteration Mechanical Behavior Evaluation Summary and Discussion}

The overall test program included over 600 experiments, including approximately 250 tensile, creep, or rupture tests, 100 crack growth tests, and over 500,000 hours of test time. The program provided many useful conclusions on optimizing the composition vs. requirements. In the first experiment, alloys ME\#12 and ME\#16 were clearly superior in creep strength, and in balance of creep strength vs. crack growth properties, than the other alloys. These two alloys thus served as the basis for the

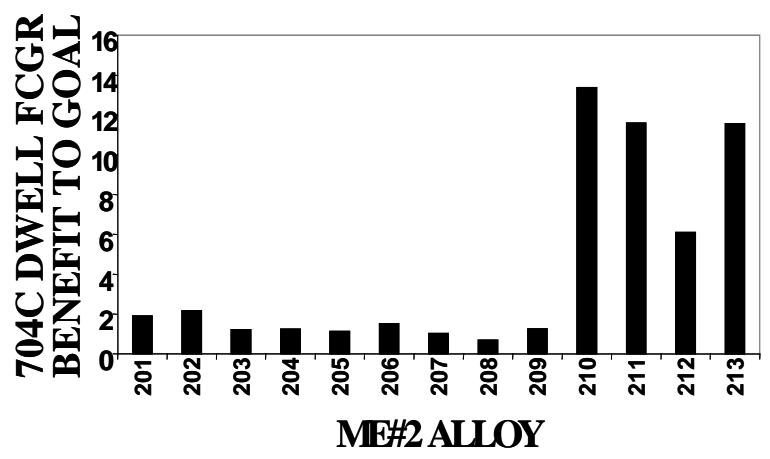

Figure 17: The L4 DOE (alloys ME2-10 through ME2-13) are clearly superior to the L9 DOE (alloys ME2-1 through ME2-9) in hold time crack growth.

second ME\#2 study. In the ME\#2 study, the relative differences between alloys were not as great. This reflects to an extent the optimization nature of the second matrix compared to the exploratory nature of the first matrix; use of multiple iterations to narrow the choice to final composition is a fundamental part of good DOE design. Even with the smaller differences between alloys in ME\#2, trends were still observed, however. Statistically observed trends are shown in Figure 18.

The overall results showed that Ta was a potent alloy for dwell crack growth behavior, while Al:Ti ratio had to be controlled to 
retain as much creep as possible. Mg was also shown to have a potent impact on strength but $\mathrm{Mg}$ is difficult to control in production so the team did not attempt to closely regulate $\mathrm{Mg}$ in the final composition. On the other hand, some elements, noticeably Cobalt, had significant influence on processability. Several of the alloys were able to achieve the challenging combination of sufficient creep in combination with acceptable crack growth behavior. This accomplishment is shown in Figure 20.

\begin{tabular}{|l|c|c|c|c|c|c|c|}
\hline \multirow{2}{*}{ Characteristic } & \multicolumn{7}{|c|}{ Element } \\
\cline { 2 - 9 } & Al:Ti & B & Co & Mg & Nb & Ta & W \\
\hline Ultimate Tensile Strength & - & & & + & & - & \\
\hline $0.2 \%$ Creep Life & - & & & - & & & \\
\hline Dwell Fatigue Crack Growth & & & & - & & + & \\
\hline 20 cpm Fatigue Crack Growth & & & & & & + & \\
\hline Supersolvus Grain Size & & & & + & & - & \\
\hline Solvus Temperature & + & & + & & & & \\
\hline Thermally Induced Porosity & & & & & + & + & + \\
\hline + indicates improvement in property or processing characteristic \\
\hline - indicates negative impact on property or processing characteristic \\
\hline
\end{tabular}

Figure 18: Observed Trends of Alloy Element Influence on Properties

Alloy ME2-9, the L9 centerpoint alloy, was the best compromise for the various processing options and the wide range of properties required for a successful application of a new disk alloy. Typical $\gamma^{\prime}$ precipitate microstructures observed in ME2-9 are shown in Fig. 19. In addition to ME2-9, alloys ME23, ME2-7 and ME2-13 all had excellent balanced behavior.

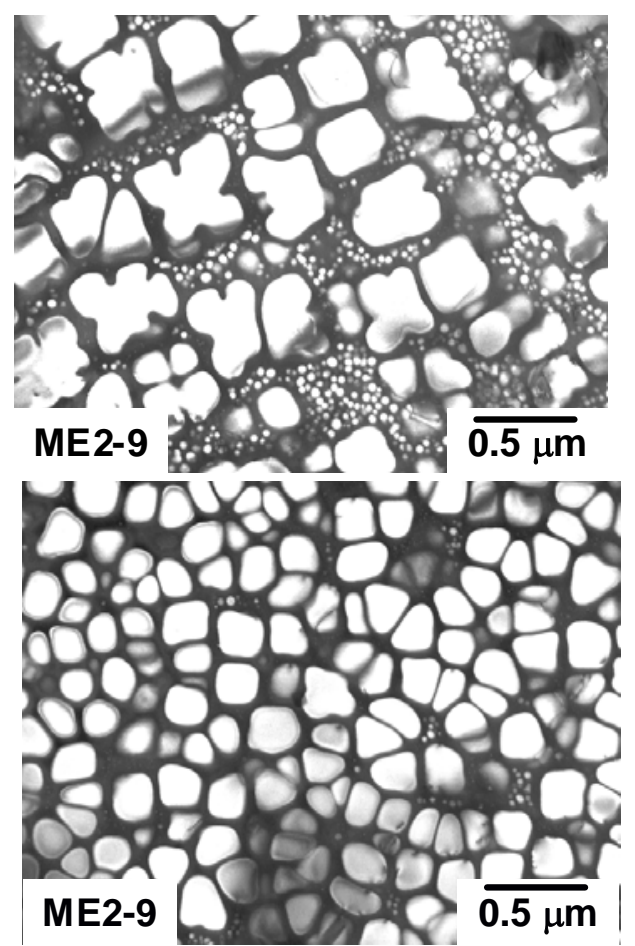

Figure 19: ME2-9 $\gamma$ ' microstructure after slow cool (top) and fast quench (bottom) cooling, with standard aging.

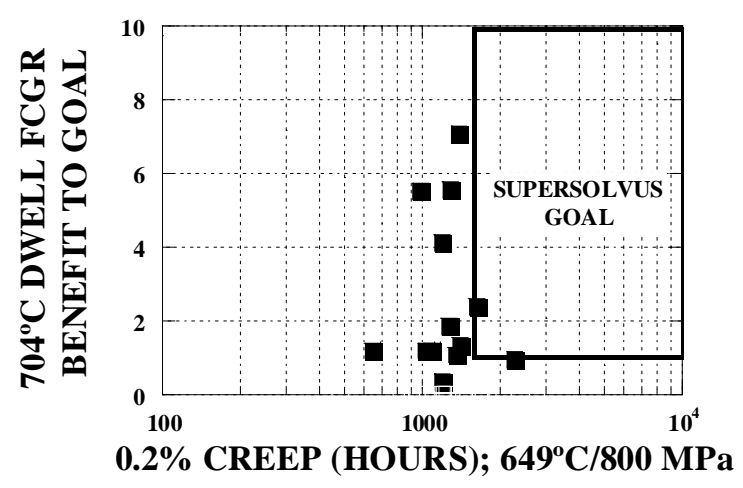

Figure 20: High temperature capabilities of the 13 ME\#2 DOE alloys are represented using a plot of creep versus dwell FCGR. Several alloys meet the goal.

Overall the results suggested a relatively high Co and Ta content, $\mathrm{Nb}$ on the high end of the range explored, $\mathrm{W}$ at an intermediate level, and $\mathrm{Al} / \mathrm{Ti}$ at close to a ratio of $1: 1$. These four alloys were used as a basis for further scaleup activity by both P\&W and GE.

\section{Acknowledgements}

The authors gratefully acknowledge the financial support of NASA Glenn Research Center, under Government contract NAS3-26385. This program was a collaborative one with both GE and Pratt \& Whitney as contractors for the effort, and the key contributions of the core P\&W team, Jack Schirra, Paul Reynolds, and Rick Montero, are also acknowledged. The sustained effort and effective team approach between NASA and both contractors for the HSCT program led to significant advances in understanding relationships between $\mathrm{P} / \mathrm{M}$ superalloy composition and processing and high temperature, long dwell properties. For NASA, Robert Draper was the focal point for the majority of the program; Draper was assisted by many colleagues, in particular Jack Telesman, Anita Garg, and David Ellis. The authors also acknowledge support of many colleagues including Bob VanStone, Joseph Heaney, Ron Tolbert and David Miller of GE; Herb Chin of P\&W; and Mei Ling Henne, formerly of P\&W and now at PCC.

\section{References}

1. E. S. Huron et. al., "The Influence of Grain Boundary Elements on Properties and Microstructures of P/M Nickel Base Superalloys”, Superalloys 2004, TMS, Warrendale, PA, 2004, pp. 73-82.

2. J. J. Schirra et. al., "Effect of Microstructure (and Heat Treatment) on the 649C Properties of Advanced PM Superalloy Disk Materials”, Superalloys 2004, TMS, Warrendale, PA, 2004, pp. 341-350.

3. R. H. Lochner and J. E. Matar, Designing for Quality: An Introduction to the Best of Taguchi and Western Methods of Statistical Experimental Design, Quality Resources Division of Kraus Limited, White Plains, New York, 1990, p. 44. 